\title{
Latino immigrant families learning with digital media across settings and generations
}

\author{
Amber Maria Levinson \\ amlevinson@stanford.edu \\ Stanford University
}

\section{Brigid Barron}

barronbj@stanford.edu

Stanford University

\begin{abstract}
This article shares case studies from in-depth research that investigates Latino immigrant families' use of technology, focusing on family technology practices that were interestdriven, cross-setting, and in some cases also collaborative among family members. Three cases illustrate ways that families-all of whom included elementary school-age childrenwere innovative in their use of technology to learn, as well as how digital resources served to help children and parents explore content across settings. Beyond documenting families' existing practices, the study also examined what happened when each family received a tablet device with curated language- and literacy-related content. We focus on three types of connections that families made: 1) aligning access to rich content at home and school leading to more exploration of academically relevant material; 2) expanding parents' roles as collaborative learners of English as a second language among other topics; and 3) digital production that connects civic, STEM, and language practices. We highlight ways in which families used innovative approaches to get the most out of the devices and content they had access to. We also explore how factors including technology infrastructure, opacity of the app marketplace, and cost can constrain families' opportunities to learn with technology.
\end{abstract}

\section{Keywords}

Latino immigrant families, media, technology, learning. 


\section{Introduction}

\section{a. Background}

Digital media is increasingly prevalent in the lives of young people and their families, but we are only beginning to understand its role in family practices and learning, particularly with regard to minority and marginalized groups. The United States is home to a large population of low-income Hispanic-Latino immigrant families who may stand to benefit in particular from the opportunities that digital media can offer, including (but not limited to) the area of language and literacy. Hispanic-Latino immigrant communities in the U.S. are often economically disadvantaged, and children meet with unusually stark challenges in school (Gándara \& Mordechai, 2017; Vaala, 2013). Although popular belief might imagine that school-age children quickly "absorb" a new language with little effort, in-depth research has shown that for Latino immigrant children, becoming a competent English user is often a long and challenging journey that is not adequately supported in schools (Valdés, Capitelli, \& Álvarez, 2011).

At the same time, Latino families in the U.S. are frequent users of broadcast media and are adopting digital technologies at rapid rates (Brown, López, \& López, 2016; López, González-Barrera \& Patten, 2013). There is potential to use technology to help support better connections between home and school (U.S. Department of Education, 2017; see Penuel, Kim, Michalchik, Lewis, Means, Murphy, Korbak, Whaley, \& Allen, 2002, for an earlier review). However, in order to do this we need to better understand how technology might help bridge the home-school disconnects that immigrant families experience. As an example, researchers in the "Early Window Project," documenting the impact of the children's television show Sesame Street, found that many Spanishspeaking parents reported watching Sesame Street along with their children as a way of learning English themselves (Wright, Huston, Murphy, St. Peters, Piñon, Scantlin, \& Kotler, 2001).

While families have increasing access to technology, and this technology can in turn offer access to learning resources, we know relatively little about how families are actually utilizing technology, what existing media practices in homes look like, and how new resources could support families' learning and development. Recent survey research has shown that 94 per cent of middle- and lower-income families access the internet in some way, although 23 per cent rely on mobile-only access, which can be limiting (Rideout \& Katz, 2016). Parents surveyed across the U.S. have expressed a desire for more information about finding educational media for their children, and this desire is particularly strong among Hispanic-Latino parents (Rideout, 2014; Lee \& Barron, 2015). In-depth, qualitative research can shed light on families' existing practices with technology, and areas where they may benefit from support.

Given that in immigrant families both adults and children may be acquiring a second language in parallel, the question also arises of whether media might provide opportunities for these families to learn intergenerationally. Intergenerational learning has been used to describe various processesways that adults transmit practices and beliefs to children, as well as how parents and children learn bi-directionally from one another (Gadsden \& Hall, 1996). In some cases the term has been used to describe ways that children can transmit concepts they learn to their parents or other adults in their family (e.g. Vaughan, Gack, Solorazano, \& Ray, 2003). With regard to immigrant families specifically, Katz (2014) describes how children "broker" online information for their parents. The present research considers the ways in which adults and children can learn togetherwhether collaboratively or in parallel-as well as from one another, in the context of family culture and life (e.g. Kenner, Ruby, Gregory, Jessel, \& Arju, 2007). We build on empirical work which has found that parents support children by enacting a variety of learning partner roles (Barron, Martin, Takeuchi, \& Fithian, 2009) as they support children's learning to create digital projects with 
technology. The notion of families as a unique type of creative ensemble (John-Steiner, 2000) invites researchers and designers to expand our units of analysis to conceptualize parents, grandparents, and children as potential members of extended digital learning teams (Katz, 2017). In this framing, parents and children have unique and complementary funds of knowledge (Moll, Amanti, Neff, \& Gonzalez, 1992) to share depending on how they have been positioned to learn at school, at work, and through informal opportunities with friends or community-based organizations. We draw on a learning ecology framework that conceptualizes a learner's environment as distributed across settings and time. Learning ecologies are dynamic, social, and comprised of configurations of activities, material resources and relationships, located in co-located physical or virtual spaces that provide opportunities for learning (Barron, 2006). In keeping with this background, this study was designed to look across settings and interactions, including media use itself, asynchronous interactions related to the media content that may happen at different times and places, and the variety of actors and relationships that together contribute to learning and development through joint media engagement (Stevens \& Penuel, 2010; Takeuchi \& Stevens, 2011).

\section{b. Article overview}

This article shares cases of three first-generation Hispanic-Latino elementary school aged children and their families and investigates their practices with technology, in particular the way they engaged with media across time and physical settings, both for children individually and in intergenerational practices that involved parents. In doing so we examine the role of the child, the parent, and the media content in the interaction. Understanding these practices is particularly important given the "disconnect" between home and school settings (Valdés, 1996; Goldenberg, Gallimore, \& Reese, 2005) that may further disadvantage families that are already under-served. The cases, drawn from a larger ethnographic study (Levinson, 2014), include baseline observations and observations following the provision of a tablet with curated content to each family.

We focus on three ways that the digital assets catalyzed and expanded learning activities across settings: 1) alignment of rich content at home and school led to more child-led exploration of academically relevant material; 2) parents' roles as learning partners grew to include episodes of collaborative learning of English as a second language and co-exploration of other academically relevant topics; and 3) opportunities digital production activities provided to connect civic, STEM, and language practices. In addition to sharing examples of these three catalysts for connection we also explore how other factors including technology infrastructure, opacity of the app marketplace, and cost can constrain families' opportunities to learn with technology.

Prior reports based on the larger study highlighted how the families used technology to bridge home and school settings, specifically to facilitate parent understanding through translation of homework assignments from English into Spanish, to support parents' own skills in order to help children with math and literacy skills, as well as to support children's academic interests (Levinson, 2017). In this article we focus on activities that were linked to parents' and children's interestdriven pursuits that crossed settings (whether home-school or otherwise), and in some cases were also collaborative among family members. We explore in particular the ways that children and parents used digital devices to explore content across settings. 


\section{Methods}

The data presented in this article are drawn from in-depth ethnographic mixed methods case study research with seven low-income Latino families that focused on their language and literacy experiences with broadcast and digital media (Levinson, 2014). Prior nationally-representative survey work in the U.S. had found that the presence of computers in the home was linked to higher achievement scores in grades K-3 among language-minority, largely Spanish-speaking children, but it was unclear how families were using the technology and why this relationship might exist (Espinosa, Laffey, \& Whittaker, 2006). To help fill this gap in the research, the present study used ethnographic methods to help provide the in-depth, qualitative understanding of what technology use might look like among immigrant families with young children.

In addition to understanding families' existing practices with technology, this study also endeavored to understand what might be possible if all families had access to a tablet device with curated educational content. For this purpose, the tablet "intervention" was implemented as part of the study. The ethnographic data collection documented the role of the iPad in families' technology routines during the latter half of the study. Quantitative methods were also used to gather and analyze app use data from the families' iPads. These iPad logs, besides adding quantitative app use data, also served as a prompt for interviews with families (e.g. asking them about the apps they used most, who used them, and how).

The research questions for this study included:

1. What language- and literacy-related media practices and activities do families engage in, either solo or together, as part of their daily routines?

2. What family dynamics and practices develop around a newly introduced tablet device loaded with a small set of high quality literacy and language resources?

In this article specifically, we focus on examples from the results that include interest-driven, cross-setting and intergenerational practices.

\section{a. Participants}

Study participants were seven low-income Hispanic-Latino families with young children, living in a Northern California urban area. All families, who were recruited via community-based parent outreach programs, spoke Spanish as their primary home language. Each family had at least one child between the ages of five and seven years old, and some had older or younger siblings ages of two to nine. All school-age children were enrolled in public elementary schools. One of the families had separated parents, the others were two-parent households. Parent education levels ranged from third grade level to college coursework.

This article shares examples of media practices from three of the seven participating families. These specific cases were chosen due to the variety of practices they illustrate. Of the three case families portrayed in this article, two were of Mexican origin and one was of Salvadoran origin. The parents in these families had been in the U.S. for seven to ten years and all of the children were U.S.-born (first generation). Parents worked in industries such as carpentry, food service, cleaning, and grocery stocking. The study did not formally assess family members' language proficiency, but participating fathers all considered themselves to be somewhat proficient in English. Only one of 
the mothers felt that she was somewhat proficient (see case study of Jessica, below), the rest of the mothers considered themselves to have very limited English proficiency.

\section{b. Procedures}

Data were collected over a six-month period (late 2013 to early 2014), in which the researcher (Levinson) visited each family's home every two weeks for 1.5 to 2 hours. During this time, observational data were collected using audio recording and field notes, and interviews were conducted with parents and children about their media and technology use. After the third month of data collection, an "intervention" was implemented in which each family received a tablet device (iPad) loaded with a selection of language- and literacy-related apps, as well as a brief demonstration of how each app worked. During the remaining three months of data collection, the observations and interviews continued, now also documenting the role the new device and content took on in everyday family life and learning. The apps installed on the tablets given to families included ebooks (both individual ebook apps and a digital library app), creative storytelling apps, phonics apps, and geography/nature apps, among others. Spanish language resources were included where possible, but offerings on the AppStore were much more limited than with English language apps.

To answer the research questions, case studies provide rich data regarding families' existing media ecologies and practices, while the tablet "intervention" gives a glimpse of the opportunities and/or challenges a new technology can bring and how families take up new media tools. Families received their tablets halfway through the six-month data collection period, so that families' existing practices could be documented first, and then compared with practices after the iPad was introduced.

Qualitative data collected per family included two audio recorded parent interviews, one video recorded child "artifact-based" interview, and home observations. Quantitative data included app use data from the families' tablets. In addition reading logs were collected from the Reading Rainbow ebook app that reported on the book titles families were reading and how long they spent with each book. All interviews and communication with families were in Spanish; quotes shared in this article have been translated into English. Qualitative data collected were analyzed using a grounded theory approach (Charmaz, 2006) to identify emergent themes and develop a coding scheme. Using this scheme, the data were coded in Dedoose software. Quantitative data from families' iPads were analyzed in SPSS software and provided descriptive information including which apps families used, how many times they were opened, and for how long they were open each time they were used.

\section{Results: Three Cases}

The three case studies below highlight examples in which children and their parents used technology to learn across physical settings, activities, and time. These examples include ways that families were already using the tools they had, documented in the first phase of the study before families received their iPads, as well as new practices documented in the second phase, that emerged after families received their iPads and the educational content installed on them. 


\section{a. Jessica: Exploring science at home, in school, and with library resources}

Seven-year-old Jessica lives with her mother and three-year-old sister, and spends time with her father on some evenings and weekends. A second-grader in a Spanish immersion public elementary school, daughter of Mexican parents, Jessica is competent in both Spanish and English, and enjoys hula hooping and watching the cartoon show Monster High. The only working digital devices in her home were two smartphones-her mother's phone and an older model that the girls used with the family's home wi-fi.

When asked what she'd like to do when she grows up, Jessica did not hesitate in her response: she wanted to be a scientist. Science was Jessica's favorite subject in school, and she already turned to traditional books as a resource for expanding on her interest. Among the literacy-related activities she and her family engaged in outside of school, Jessica enjoyed checking out science-related books (in addition to others) from the public library. For example, Jessica brought home a book on science experiments to do at home, such as making a baking soda volcano, which she was excited to try out.

\section{Existing media practices (a.a)}

Much of Jessica and her sister's media use consisted of playing games watching YouTube ${ }^{1}$ videos on smartphones. Jessica's three-year-old sister Yelitza still enjoyed many of the educational titles their mother picked out for them including Dora the Explorer, Go Diego Go! and Superwhy. At almost seven years old, Jessica now preferred watching programs with an older target audience, including Monster High and My Little Pony. The girls also played app games such as Candy Crush ${ }^{2}$ and a Barbie-themed doll dress-up game. Jessica also played a chess app.

Jessica's mother Rebeca, who immigrated to the U.S. as a young adult, used her smartphone for her own learning, including to do research for her GED class assignments and for new words in English. She also used YouTube to look up instructional videos to brush up on her own skills so that she could support Jessica with her homework. Jessica, in turn, understood that the internet could be used as a reference tool; for example when she wanted to know the Spanish equivalent for "jelly bean," a word she used with friends in school, she asked her mother to look it up online.

\section{New practices with the provided tablet (a.b)}

With the iPad that Jessica and her family received as part of the study, Jessica used the tablet in the same ways that she used the family's smartphones, but she also added new practices that were offered via the new content loaded on the tablet. She regularly used the Reading Rainbow app (later renamed Skybrary ${ }^{3}$ ), a digital book library of hundreds of children's ebooks organized by theme on "islands," including "Action Adventures \& Magical Tales" and "Animal Kingdom." Reading Rainbow, which offers an optional voice narration feature, was the single most-used app among those that were provided on families' iPads. Jessica, like most of the children and parents participating in the study, had never engaged with an ebook before participating in the study. Jessica's mother, Rebeca, used the app to listen and read along with Jessica and her younger sister, which she liked in part because she felt it helped support her own English learning:

Rebeca: In English it helps me to see how they pronounce it and to be able to help [my daughters] too. [...] because I put it on, it gives you the option of reading it yourself or

\footnotetext{
${ }^{1}$ http://www.youtube.com

${ }^{2}$ http://itunes.apple.com/us/app/candy-crush-saga/id553834731? mt=8

3 http://www.levarburtonkids.com/skybrary
} 
having the iPad read it, so I have the iPad read it first and once it reads it to us, then I read it, because I hear the, how do you say...

A: The pronunciation?

$R$ : The pronunciation. [...]

$R$ : Because the book goes slowly, it reads slowly and in the cartoons they go fast and here no, if I don't understand something I go back and repeat it.

A: Repeat what it's saying.

$R$ : Yes and also you're reading the words too, so it's easier to remember them.

In this joint reading practice, Rebeca positioned herself as learning partner, (Barron et al., 2009), engaging in an activity with her daughters and learning alongside them. Although Rebeca was learning alongside her daughters in this activity, as do Barron et al.'s (2009) "collaborators," Rebeca had her own parallel but different learning goals as part of the reading time.

An interesting contrast emerged when Jessica and her mother both began to use Duolingo ${ }^{4}$ (English), another app that was installed on the tablets. This language learning app, rather than creating a collaborative experience for mother and daughter, was a source of some competitiveness between the two. Rebeca, who was less competent in English than her daughter, expressed that she did not like for Jessica to advance past her own level. "I tell her not to advance past the levels I'm at," Rebeca explained, "to wait until I've passed them [myself]." The app activities are mostly based on completing or translating sentences, and do not require or offer any particular content knowledge. Rather than play together, Jessica and her mother used Duolingo separately. In contrast, the ebook co-reading activity facilitated an experience where both Jessica and her mother could engage together and Rebeca could use the spoken narration feature to review pronunciation before she began to read to the girls herself.

Ebooks from the Reading Rainbow library app were one of the family's main activities with the tablet and according to the app use data, the family spent 1,329 minutes (over 22 hours, or an average of 110 minutes per week) with the app in three months of the tablet intervention. As shown in Table 1, Jessica herself spent 448.6 minutes (approximately 37 minutes per week on average) with books in her own Reading Rainbow "backpack." This time does not include the time spent on the app's related games or video field trips, or time spent with books in her younger sister Yelitza's backpack.

\begin{tabular}{|l|l|}
\hline \multicolumn{1}{|c|}{ Book Title } & Minutes \\
\hline 36. Victor Vicuña's Volcano Vacation & 8.7 \\
\hline 35. Mail Harry to the Moon & 11.2 \\
\hline 34. A Picture Book of Abraham Lincoln & 10.2 \\
\hline 33. Deep in the Swamp & 3.7 \\
\hline 32. Let's Visit Paris! - Bella and Harry Adventures & 9.3 \\
\hline 31. Let's Visit Athens! Bella and Harry Adventures & 9.8 \\
\hline 30. Hello, Bumblebee Bat & 3.3 \\
\hline 28. The Story of Hannukah & 8.5 \\
\hline 27. The Ink Garden of Brother Theopane & 0.3 \\
\hline 26. NG Readers Snakes & 9.1 \\
\hline 25. Dinosaurs & 5.5 \\
\hline 24. NG Readers Sharks & 8.1 \\
\hline 23. A Picture Book of Harry Houdini & 0.7 \\
\hline 22. Beauty and the Beaks: A Turkey's Cautionary & 10.5 \\
\hline
\end{tabular}

${ }^{4}$ http://www.duolingo.com 


\begin{tabular}{|l|l|}
\hline Tale & \\
\hline 21. Fiona's Luck & 11.8 \\
\hline 20. A Picture Book of Cesar Chavez & 16.4 \\
\hline 19. Halloween Forest & 14.1 \\
\hline 18. Over at the Castle & 3.1 \\
\hline 17. Into the Deep & 6.4 \\
\hline 16. Me and My Dragon Scared of Halloween & 1.8 \\
\hline 15. NG Readers Storms & 7.9 \\
\hline 14. Miss Marin is a Martian & 16.8 \\
\hline 13. Haunted Party & 12.2 \\
\hline 12. Frances Frog's Forever Friend & 28.5 \\
\hline 11. I Like Gum & 9.6 \\
\hline 10. A Picture Book of Martin Luther King, Jr. & 17.0 \\
\hline 9. NG Readers Dolphins & 21.2 \\
\hline 8. Rapunzel & 28.1 \\
\hline 7. NG Readers Planets & 14.6 \\
\hline 6. NG Readers Volcanoes & 27.9 \\
\hline 5. NG Readers Titanic & 61.0 \\
\hline 4. The Case of Vampire Vivian & 10.9 \\
\hline 3. Sir Circumference and the Vikings Map & 0.1 \\
\hline 2. Chickerella & 23.6 \\
\hline 1. Me and My Dragon & 5.2 \\
\hline TOTAL MINUTES & $\mathbf{4 4 8 . 6}$ \\
\hline
\end{tabular}

Table 1. Jessica's Reading Rainbow Log, science books shaded.

In Jessica's case, ebook reading emerged as a home-based literacy practice that was linked to her personal and school-related interest in science. Based on the Reading Log for Jessica's own backpack, Jessica spent approximately 38 percent of her reading time with books about science topics (shown in Table 1, shaded), many of them selected from the small collection of "National Geographic Kids" titles. Jessica was one of two children in the family, and her three-year-old sister Yelitza also used the app, but had her own "backpack" on the app and Jessica's reading history does not include books from Yelitza's backpack. Though it is possible Yelitza also used Jessica's account, she had downloaded her own selection of books to that backpack and in the interview was able to navigate the app to access her collection separately from Jessica's. The science-themed books were also not among the titles that Rebeca reported co-reading with her daughters, indicating that these were resources Jessica was exploring on her own. Jessica preferred using the ebooks over the creative storytelling apps installed on the tablets, as she did not like recording her voice.

\section{b. Brandon: Using technology for collaborative inquiry}

Brandon is an active six-year-old boy who loves to play outside as well as play video and board games. He attends first grade in a Spanish immersion program at a public school near his family's apartment. Brandon speaks predominantly Spanish although his parents report based on observing him at school that he understands and speaks some English as well.

Brandon's family owned many digital devices despite limited financial resources. Their investment in media and technology was driven in large part by the need to be in contact with family overseas; both of Brandon's parents had older children in El Salvador that they supported from afar, along with Brandon's grandparents and other relatives. Smartphones, a laptop, a desktop computer, and wireless internet were used for direct contact with those family members who had technology. An international cable TV package helped Brandon's parents keep up to date on news from Central America. 


\section{Existing media practices (b.a)}

Brandon had a keen interest in people in history. Brandon often asked his parents questions about famous people that had been presented in school, either because of a particular holiday such as Martin Luther King Jr. Day or other thematic units his first grade class was studying at the time. Brandon developed a practice with his father José, in which the two used his father's smartphone to search for videos on YouTube about Martin Luther King, Jr., George Washington and other famous leaders Brandon wanted to know about in the moment. Brandon's father José, having grown up in El Salvador with a different history curriculum, did not have many of the answers that Brandon sought about US historical figures, and the two turned to YouTube as a way of learning more. As José explained:

So, well, for him to... because he also asks us a lot about César Chavez, about Martin Luther King, Washington, about all of them... because I imagine that at school they mention them and he comes home with that idea or wants to see what they are like, sometimes [online] there are videos with photos, sometimes there are videos where Martin Luther King is talking, and that way he gets an idea of who he is, and he starts realizing who the person is.

Although numerous text resources are available online about any of these important names in history, in José's view videos provided a way of representing information that was easier for Brandon to connect to at his age.

Because it's easier for him, for him to visualize it and understand it better, and everything, and as adults sometimes we read and understand things better. But sometimes if we're given something to read, sometimes we don't understand it well. And this way [on the videos] they represent it or... like he understands the how people are portrayed better that way.

Though José and Brandon began exploring YouTube videos in order to learn about history-related topics, they expanded this practice to explore other topics. Brandon was also interested in animals, so father and son engaged in collaborative interest-driven searches (Barron \& Levinson, 2017) on various species. José described one instance in which Brandon's questions were actually sparked by watching media - one of the Disney Ice Age movies. "He said 'Dad, at that time what was it like, there weren't any buses, there weren't...?,' so we watched documentaries where it shows [what it was like] and everything." In this way, media and particularly Internet video became a go-to resource for Brandon and José to learn about topics Brandon was interested in, taking advantage of the information available as well as the visual nature of the material and seeing footage of historical figures in action, as with Martin Luther King, Jr. giving speeches.

Learning new words in English was also a goal of joint inquiry between Brandon and his father. At school, Brandon was enrolled in a dual immersion program where the majority of his instruction was in Spanish, but he was exposed to English via his peers and certain classes held in English. At home, Brandon would often repeat English words he had heard but didn't understand, and ask his father what they meant. With the speech to text feature on Google Translate ${ }^{5}$ using Josés smartphone, the pair spoke words into the microphone and explored the translation on the app.

\footnotetext{
${ }^{5}$ http://play.google.com/store/apps/details?id=com.google.android.apps.translate
} 


\section{New practices with the provided tablet. (b.b)}

Several weeks after his family received their tablet as part of the study, Brandon discovered the David A. Adler Picture Book Biography Series of books on the Reading Rainbow e-library. The series, which like others in the app also exists in print form, is made up of several individual illustrated life stories of Benjamin Franklin, Helen Keller, Martin Luther King, Jr. and others, some of whom Brandon had learned about in school. Reading these books on Reading Rainbow at home, Brandon developed another avenue to explore his interest in historical figures. Brandon's parents had already explained that this interest had originated in school. A further connection surfaced when Brandon was asked about why he had chosen to download the Benjamin Franklin ebook on Reading Rainbow. Brandon responded, "Because my teacher has all those books," pointing to the five books in his Reading Rainbow backpack, all from the same Picture Book Biography series. Brandon's explanation suggested that the books had attracted him not only due to his interest in famous people, but because they were from the same series his teacher had on the book shelves at a school and that he was already familiar with.

Overall, Brandon spent 159.4 minutes with ebooks on Reading Rainbow. He also spent another 135 minutes browsing the books and doing the supplemental activities (such as the video field trips) and 164 minutes with other ebook apps provided on the iPad. In the last month of the study, Brandon had downloaded five books from the series on historical figures (shown in Table 2, shaded). The study could only follow his reading pursuits up to this point because he began downloading the biographical books near the end of the data collection period. They were among the most recent of the 22 books Brandon accessed during the study, and his time reading these books totaled 27 per cent of his total reading time on the app.

\begin{tabular}{|l|l|}
\hline Book Title & Minutes \\
\hline 22. A Picture Book of Martin Luther King, Jr. & 8.9 \\
\hline 21. A Picture Book of Helen Keller & 5.8 \\
\hline 20. A Picture Book of Thomas Alva Edison & 0.1 \\
\hline 19. A Picture Book of George Washington & 1.8 \\
\hline 18. NG Readers Penguins & 0.9 \\
\hline 17. First Dog & 1.9 \\
\hline 16. A Picture Book of Benjamin Franklin & 26.7 \\
\hline 15. Look and Learn Same and Different & 3.1 \\
\hline 14. Kylie Kangaroo's Karate Kickers & 17.1 \\
\hline 13. Look and Learn Shapes! & 1.2 \\
\hline 12. First Day Jitters & .6 \\
\hline 11. NG Readers Planets & 5.7 \\
\hline 10. Haunted Party & 7.6 \\
\hline 9. The Searcher and the Old Tree & 4.6 \\
\hline 8. Hershel and the Hannukah Goblins & 8.3 \\
\hline 7. The Three Bears Christmas & 4.8 \\
\hline 6. Dinosaurs & 9.1 \\
\hline 5. A Mother's Journey & 12.0 \\
\hline 4. Blue-Ribbon Dad & 4.8 \\
\hline 3. The Three Bears Halloween & 25.2 \\
\hline 2. Young Henry and the Dragon & 5.4 \\
\hline
\end{tabular}




\begin{tabular}{|l|l|}
\hline 1. Halloween Forest & 3.8 \\
\hline TOTAL MINUTES & $\mathbf{1 5 9 . 4}$ \\
\hline
\end{tabular}

Table 2. Brandon's Reading Rainbow log, biographical books shaded.

In addition to reading ebooks that connected to his historical interests and to his classroom library, Brandon also used apps on the tablet to explore geographical places of interest, making a connection between the "real world" and the map interface, as well as connecting to content on different apps. For example, Brandon used Google Earth ${ }^{6}$ to explore his own neighborhood, find his house and school, and locate other places familiar to him. He also used the app Barefoot Atlas ${ }^{7}$ to explore information about a variety of places and then used Google Earth to view them from a different perspective. For instance, after learning about France on Barefoot Atlas, Brandon asked his father how to spell "France" and then entered the word into Google Earth to explore the country that way. On another day, he brought his soccer ball, which had "Mexico" printed on it, to the table and copied the word "Mexico" into Google Maps", where he then "flew" around to different parts of Mexico and zoomed in to examine selected areas.

\section{Naomi: Creator and producer}

Naomi, eight years old, enjoys reading, crafts, playing the role of reporter and producing her own media. Her six-year-old brother Eduardo enjoys being a collaborator on Naomi's media productions. Naomi's parents Lorena and Eduardo immigrated to the US together before their children were born. They support both their children's individual interests, enrolling Eduardo Jr. in sports activities whenever possible and stimulating Naomi's interest in communication and creative pursuits.

\section{Existing media practices (c.a)}

Naomi and her brother Eduardo Jr. often chose different media to watch or play, but producing media was an activity they enjoyed doing together. Naomi's father Eduardo, a carpenter, had studied communications in college in Mexico and encouraged his children to create their own media:

Eduardo (Naomi's dad): I've been interested in that, in photography. So I'll show [the children] photos I take, how I can improve them and all that. I've always liked photography. It's an interest I try to instill in them. So I might try to teach them a song I like a lot, and I try to say to them, 'Would you like to play the guitar like [the musician] is playing?' And they say, 'No, yes, it sounds cool,' and so...

I: Do they play instruments?

Eduardo: No, but I tell them, I try to tell them that when the time comes that they can take guitar or piano lessons. So I try to tell them that, because I've always loved music, photography, film, videos, making videos. So I have told them too, for example, 'you can start making your video with the phone,' and that's why Naomi is starting to want to report and record.

The media Naomi watched was also influential in the style she chose for her videos. Naomi enjoyed the Nickelodeon program iCarly ${ }^{9}$, a teen show about a girl who produced her own webcast along with her group of friends. Using her own iPod touch, Naomi created "shows" featuring herself in the

\footnotetext{
${ }^{6}$ http://earth.google.com

7 http://barefootworldatlas.com

8 http://maps.google.com

9 http://www.nick.com/icarly/
} 
role of presenter (as Carly and other characters on iCarly often did) and incorporating her six-yearold brother Eduardo as cameraman or as a "guest" on the show. Although iCarly is in English, Naomi and Eduardo narrated the shows in Spanish (translated in the excerpts below). Some elements of Naomi's style are reminiscent of on-location television newscasts or talk shows, and may be linked to watching these common genres as well.

Naomi: Welcome back, now we will be talking about nature. Here there are many examples of nature. The way you can take care of the ocean, not litter, or... keeping all plants safe. As we can see, this tree is so pretty on my street [camera shows tree outside bedroom window] that there's even a hummingbird, there's one right here.

Eduardo Jr.: You see? If you are in Mexico it doesn't matter, we will send it to you on Facebook. There are [referring to street scene below] all the cars that... are in [city]. There is a biker, the leaves, and farther down there is our school. And we can also see people crossing the street, the trees, the school where I used to go, and that way [speaks inaudibly to Naomi]. Farther that way past the freeway is where my aunt and cousin live.

As Naomi and Eduardo narrate their video, they naturally interweave the local and the global in their subject matter; bringing together a topic of widespread concern (preserving the environment) as well as details of their local surroundings. Eduardo also makes a direct reference to the video audience, including family or friends in Mexico ("it doesn't matter if you are in Mexico, we'll send it to you on Facebook").

Naomi and her brother's productions also brought out themes that were emphasized at their school, which has an environmental science focus. In the excerpt below, from the same "episode" as above, the siblings issue a message for viewers about protecting the environment and aquatic species:

Naomi: Now, how you can help the earth is by recycling, using many kinds ofEduardo Jr: When you go to the sea-

Naomi: To the beach. Very good, Eduardo, that is a good thing. You can recycle things, not throw them into the sea. Because there are many animals, and they can eat it and [Naomi rolls her eyes back in her head and grasps her throat as if choking] They choke! Eduardo Jr: They stay there, and Naomi: No one wants that, because [crosstalk with Eduardo] animals can do something good for us...

Eduardo Jr: They are killing the salmon, they're not born in time-

Naomi: And also, please, tell your parents, friends, they should know it's very urgent: never kill a whale. There aren't many left.

In this way, Naomi's video production activities formed a conduit between school-based discussions and the home environment, surfacing in an artifact shared with parents and relatives that included a civically oriented message that encouraged conservation, recycling, and protection of vulnerable species.

While iCarly inspired Naomi's media production, another video resource led Naomi to develop an interest in a hands-on activity. Naomi began watching a series of DIY ("do it yourself") instructional videos in English for building elaborate environments, accessories, buildings and furniture for dolls. She discovered the series by accident, following a series of YouTube video suggestions-from the popular cartoon program Monster High (her initial search on YouTube) to another show called 
Seven Supergirls. When Naomi was done watching the latter, a video from My Froggy Stuff ${ }^{10}$, a YouTube channel with instructional videos, appeared as a suggestion for further viewing. Naomi became interested in the detailed projects the videos demonstrate how to build, step-by-step and using low-cost everyday materials.

Naomi: It's called My Froggy Stuff. It teaches you how to make things, like... how to make a doll cash register, a dollhouse, [reading from screen, in English]: "how to make a doll Kawaii hat and beanie, how to make doll popsicles." One thing that I like and that I want to do with my mom is "how to make a doll treehouse." [...] [My mom said] to try to write down what I need to make it. But most of it is easy to make. [...] and almost everything, I have it. Like cardboard.

My Froggy Stuff connected Naomi's interest in dolls with a creative and constructive activity that the instructional videos inspired and supported. Naomi's mother encouraged her interest, and instructed Naomi to write down the materials she needed to make the doll tree house so that they could build it. Although the My Froggy Stuff videos are not intended for language or literacy instruction, Naomi was using them to engage in self-guided, interest-driven learning, in this case through oral instruction in English. This example also illustrates how one media genre (a noneducational cartoon show) led to engagement in an interest-based, hands-on activity, in this case via the YouTube suggestions for further viewing.

\section{New practices with the provided tablet (c.b)}

By the end of her participation in the study, Naomi had begun to understand how to make a multiscene story using Toontastic ${ }^{11}$, one of the creative storytelling apps that came pre-installed on the iPad her family received. Toontastic allows children to choose characters, move them on the screen, and audio record one's own narration or dramatic scene. It also guides users to structure their stories in a traditional narrative arc, with a "setup," "conflict," "climax," and "resolution" scene. The narrative scaffolds were lost on many of many of the younger participating children, who created each scene as a distinct story. Naomi however attended to the instructions and created series of scenes that built on one another.

While other children in the study also used the creative storytelling apps on their tablets, Naomi's productions in particular highlight the cross-setting links driven by her interest in video production and reporting, as well as civic action and the environment. In creating Toontastic cartoons, the app gives users a choice of backdrops for their stories. Naomi enjoyed using the talk show setting, and role playing television presenters, reflecting the interest that surfaced through her own talk show production. In the following excerpt Naomi demonstrates how she used Toontastic and opened the app to create a new cartoon (translated here from Spanish):

Naomi: I want to be... uh... [scrolling through the available backdrops on Toontastic]. Where is it? Where they're interviewing. [Chooses the TV studio setting entitled "The Way Past Your Bedtime Show," and chooses two characters: a reporter and a second character wearing a winter outfit].

Naomi: [simultaneously with app voice]: 3, 2, 1, Action!

Naomi: [moving reporter character]: Now we are reporting with our friend who comes from the south to New York. [Naomi makes audience cheering sounds, then acts out both characters]:

\footnotetext{
${ }^{10}$ https://www.youtube.com/user/MyFroggyStuff

${ }^{11}$ https://toontastic.withgoogle.com/. Note that at the time of the study Toontastic was a 2D app and was not yet affiliated with Google.
} 
'Hello, my name is Sandy Moy, and I come from the south all the way to New York.' 'Well, tell us Sandy Moy, oh, I am... I am Barbara Gordon.'

'I come from the south because that's where I live. My family grew up there.'

Naomi also created a full, five-scene animation using the Toontastic play set of historical figures, telling a presidential election story, where a nobler African-American incumbent candidate, Dr. King (using Martin Luther King Jr. character), is running against a white candidate (represented by the George Washington character). In an excerpt, the candidates and their supporters discuss the presidential race, with Naomi acting out all of the parts:

Female character: I am a lawyer, and I tell you to vote for him [Dr. King character], because he is the best...

Dr. King [to opponent candidate]: But just tell the world, what will you do for them?

Other candidate: I will give money, make them have a good life, and live in houses, like rich people [evil laugh]. Mwahaha.

Female character: But I like where I live. [...] Dr. King should be the president, because he has taught the people how to be, he'll teach us all to be great people, how to make the earth better.

Naomi's Toontastic creations were another way in which her school- and community-based interests surfaced, including civics (present in her talk show video and her Toontastic election story), reporting, and environmental science.

\section{Discussion}

Digital technology has the potential to provide new opportunities for young children's learning across settings. However, few studies have been carried out that provide rich examples of how learning activities can be catalyzed with access to powerful devices, the Internet, and high quality content. In this study we highlight how introducing and providing a tablet device with curated language and literacy related content made new practices possible while building on parents' and children's existing expertise. In the cases above, we shared both how families used technology for interest-driven learning across settings, and the ways in which various learning activities engaged parents and children together based on either joint or parallel learning goals. In particular we focused on three ways that the digital assets catalyzed and expanded learning activities across settings: 1) alignment of rich content at home and school led to more exploration of academically relevant material; 2) expanding parents' roles as learning partners grew to include episodes of collaborative learning of English as a second language and co-exploration of other academically relevant topics; and 3) digital production activities that provided opportunities to connect civic, STEM, and language practices.

The three ways in which technology facilitated learning across settings and generations among these families are detailed below. In each of these categories, new content on the distributed iPads served to support and expand existing practices among families.

\section{a. Aligning rich content at home and school}

Brandon's and Jessica's cases illustrate ways that digital tools can contribute toward aligning home and school through access to content that is relevant to academic interests, and-in the case of Brandon's exploration with the biography picture books-sometimes facilitating out-of-school access to the same content available in school (in this case, a digital version of physical books that Brandon had access to in the classroom). In other instances, such as with Brandon's exploration of 
his neighborhood and the globe on Barefoot Atlas and Google Earth, apps were a means to connect different spatial representations of place and geography.

In their model of interest development, Hidi and Renninger (2006) build on and synthesize prior research on interest to delineate four progressively deepening phases: triggered situational interest, maintained situational interest, emerging (less-developed) individual interest, and welldeveloped individual interest. Each of these phases marks a window in which it can progress toward the next phase if sufficiently maintained and nurtured. Through the case and research examples shared, we illustrate how learner engagement can move across settings in building interest, and how different forms of support and information seeking can be essential. Jessica and Brandon's examples highlight some ways that ebooks contributed to interest development by providing a venue for these learners to further explore topics that they may have had a "triggered" or "maintained" situational interest in.

Reading Rainbow in particular facilitated interest-driven exploration by allowing children on their own initiative to peruse a variety of titles and select content that connected with their personal areas of interest and knowledge. The way the app is structured specifically encouraged this process by organizing the ebooks around loose topics such as "Animal Kingdom," "Awesome People," and "National Geographic Kids" (science and geography focus). In terms of exposure to spoken and written English language, in these cases the ability to seek out content based on interest may have played some role in facilitating children's interaction with ebooks and thus with these forms of language. In the home setting interest was a key factor in attracting children to ebook content. Rather than engaging in the activity in order to "learn to read," as might be emphasized in the phonics approach to literacy, common in popular educational apps (Guernsey, Levine, Chiong, \& Severns, 2012), ebook materials that overlapped with children's interests offered children the opportunity to "read to learn," or if they were using the audio narration and not always attending to the text, then at least "listening" to learn with text displayed.

Finally, although the Reading Rainbow library offered access to a far wider range of books than most children would likely have on their physical shelves at home, it is important to note that the app had a subscription cost, approximately $\$ 60$ per year at the time of the study, which may not be within the means of many low-income families had the subscription not been provided to them free of cost. Currently there are several ebook library platforms, each with its own cost structure. Some work via school subscription model that is paid by schools but offers students access at home, while some offer free access in school but home use is charged separately, and these models shift as businesses evolve. Cost structure can be an important factor in shaping how and whether lower-income families engage with ebooks as in the cases we present here. The examples shared in this paper suggest that the potential for intentional alignment between content provided at school and connected digital assets is significant and they provide further warrant for policies and practices that ensure equal access to digital resources that might benefit children and their families.

\section{b. Expanding parents' roles as collaborative learners}

Another role the technology played in families' learning interactions was as a centerpiece for intergenerational learning, where parents engaged not only as supporters of their children's learning but also as co-learners of English or other topics. Although prior research has highlighted the family media practice of interest-driven search (Barron \& Levinson, 2017) the example of Jessica's mother Rebeca using the Reading Rainbow app with her daughters to improve her own English and the example of Brandon and his father using Google Translate to explore new vocabulary highlight an interesting role that parents took on as they attempted to act as learning 
brokers for their children (Barron et al., 2009). In Jessica's case, this came about as part of a general co-reading routine, and in Brandon's case, as part of Brandon's father's attempt to help answer his son's questions. However, each parent also approached these activities with learning agendas of their own as adult learners of English.

In Naomi's case, Naomi's father Eduardo draws attention to the way he acts as a "learning partner" (Barron et al., 2009) in his daughter's pursuit of media production. Barron and colleagues identified learning partner roles that middle-class Silicon Valley parents played in their children's technology activities, including "teacher" and "learning broker" roles. Naomi's father Eduardo Sr. takes on these roles, both directly instructing Naomi and her brother in photography skills (teacher role) and providing the tools and encouragement for Naomi to create her own productions. With regard to Naomi's interest in DIY crafts via YouTube, her mother Lorena also played a "collaborator" role by encouraging Naomi to list the materials she would need and planning to build the projects along with her. These examples of the expanding intergenerational and bi-directional learning/teaching relationships within and across families hint at the potential for intentionally designing family learning opportunities to allow parents to share practices with one another. The fact that Naomi's production activities prior to receiving the tablet were fairly unique among study participants also draws attention the fundamental role that her parents, particularly her father, played in modeling, inspiring, and supporting interests. In general the variations across the case families in this study highlight the diversity among Latino immigrant families and how parents' unique histories and experiences with specific cultural practices (like media production) influenced the ways they capitalized on the digital resources they had access to.

\section{c. Digital production that connects civic, STEM, and language practices.}

The third interest-driven and cross-setting practice that emerged in the data, specifically in Naomi's case, was digital production that connected themes from home, school, and community. In their video, Naomi and Eduardo used their experience watching programs, particularly iCarly, as a template for creating their own show that shares themes from their lives and topics (such as recycling and conserving wildlife) likely introduced at school, where environmental science was a schoolwide focus. In this way Naomi and Eduardo, who consumed a variety of different media programs, also leveraged this experience to express their own voices and share-to a palpable audience-topics of concern and interest to them. This example also illustrates Dugan, Stevens, and Mehus' (2010) point that media programs that are not necessarily designed as "educational" can give rise to learning interactions and activities. In this case, Naomi used the model demonstrated by iCarly and perhaps other programs to create an activity for her and her brother that engaged their language skills and vocabulary and provided a forum to share their ideas and knowledge.

In addition to video production Naomi also developed an interest in production with physical materials, based on digital content on the My Froggy Stuff YouTube channel. In this case technology facilitated Naomi's discovery of the channel through suggested videos, and sparked her practice of building models drawn from the video channel. In this activity, Naomi moved from consuming videos to hands-on building, which she looked forward to due to her own interest but also as a way to collaborate with her mother.

When Naomi's family received their tablet, Naomi added an additional genre of production using the scaffolded storytelling apps installed on it and widening her thematic scope using the available characters and backgrounds as springboards for new pieces. Creative and expressive digital production activities are powerful for learning and interest development. However, too few children have access the ideational resources and digital tools that encourage them and there is significant 
potential for creating opportunities in school and through community organizations that might provide them.

\section{d. Constraining and enabling factors}

While this study surfaced several examples that illustrate how digital media can play a role in families' interest-driven and intergenerational learning across settings, it also revealed some factors that constrain and enable the potential for families to utilize media in these ways. Both in this article and in the larger data set (Levinson, 2017; Levinson, 2014) families showed ingenuity and inventiveness in how they harnessed the tools they had access to to learn and solve problems. However, there are also many opportunities to improve families' access to the tools themselves and information about how to use them most effectively.

First, at the most basic level access to devices and the internet is not yet equitable across communities and socioeconomic groups. Although the vast majority of lower-income families in the U.S. now access the internet in some way, as many as one in ten families below the poverty line have no internet access at all, and of those who do access the Internet about one-third only have access via mobile phone, which can limit the use of technology for learning activities (Rideout \& Katz, 2016). This trend was evidenced in this study with Jessica's family, who initially had highspeed internet but could only go online via smartphone. Two other families in the larger study did not have high speed internet and this made it more difficult to benefit from programs such as Reading Rainbow that requires going online to "check out" new books. Conversely, access to reliable, high-speed internet facilitated technology use for learning among the families that had it. Families like Brandon's, who had limited financial resources but invested heavily in technology, prioritized connection with the parents' country of origin, had the tools available to them for other learning-related purposes.

The new tablets-more precisely the new curated content that the tablets had installed on themdid lead to some new practices with technology that families had not engaged in before. It was this new content, which enabled activities such as choosing books of interest from a digital library or creating original stories, that led to the new practices, rather than features of the tablet device itself. In other words, had a tablet been provided without the curated resources, the specific new practices documented here would not have emerged in the same way. Although prior to receiving the tablets these three families had access to at least some digital devices and the internet, most did not know about content like children's ebooks or creative storytelling apps. Nationallyrepresentative surveys in the U.S. have shown that parents in general, and particularly HispanicLatino parents, desire more information about how to find and select educational media for their children (Rideout, 2014; Lee \& Barron, 2015). These findings suggest that there is an opportunity to further support parents in navigating the crowded and potentially confusing marketplace of app content and position them to intentionally curate valued content (Barron \& Levinson, 2017).

Finally, there are linguistic constraints that may also bind parents who are primary speakers of a minority language (such as Spanish in the U.S.). The availability of digital content in languages other than English is often limited, raising equity concerns (UNICEF, 2017). This trend was evidenced during the preparation for the present study, where we found very limited ebook and other educational content available in Spanish, as compared to offerings in English. As families' practices shift toward using more digital resources, this imbalance may restrict families' options to support heritage language development and to fully understand the content that they encounter. 


\section{Conclusion and Future Directions}

Given the potential for creating more equitable access to content, there is a significant need for design-relevant ethnographic work that can provide rich examples of what might be possible if all families have access to devices, connectivity, and high quality content that can connect to academic and personal interests. Novel methods for data collection might also be developed that allow researchers to quantify the use of digital assets as one way to characterize the diversification of a child's learning ecology. This study provides an example of how collecting time data in a digital reading app gave researchers the opportunity to triangulate ethnographic observations, interview data, with the digital traces of the amount of time spent with particular books.

We close with three directions for future work, as it will be important to carry out additional studies that can validate and extend the observations we offered here. First, it would be productive to test the hypothesis that content teachers share in classrooms will be further explored at home when children have free time. Building on the idea of repertoires of practice (Gutierrez \& Rogoff, 2003), a second direction might further investigate how parents shift their roles from teachers and caretakers to collaborators and co-learners when given an opportunity to participate in varied learning partner roles as they engage with novel digital resources. Future studies might also look specifically at how different families use the features of digital libraries such as optional audio narration and how these features might support families with varying learning needs and language backgrounds. Third, digital production was an extremely rich learning activity. We know from other research that making and creating is associated with social, critical, and constructive dispositions (Barron \& Martin, 2016). Future research might help us design ways to expand families' activities as producers. Already many design experiments are underway and we call for more efforts to investigate both learning environments and outcomes (e.g., Brahms \& Werner, 2013; Roque, 2016). Experience gaps start early and it is essential that we not only attend to documenting them but commit to bridging them by seeding learning at home, school, and in the many community spaces where families spend time.

\section{Acknowledgements}

This research is supported by the TELOS (Technology for Equity in Learning Opportunities), an initiative at Stanford Graduate School of Education to create and investigate ways that technology can advance equity in learning opportunities for PreK-12 students, educators, and families. The Amir Lopatin Fellowship provided generous funding to enable data collection. This research was also supported by the LIFE Science of Learning Center (Learning in Informal and Formal Environments), an NSF funded (REC-354453) effort seeking to understand and advance human learning through a simultaneous focus on implicit, informal and formal learning, thus cultivating generalizable interdisciplinary theories that can guide the design of effective new technologies and learning environments.

\section{References}

Barron. B. (2006). Interest and self-sustained learning as catalysts of development: A learning ecology perspective. Human Development, 49, 193-224.

Barron, B., Martin, C. K., Takeuchi, L., \& Fithian, R. (2009). Parents as learning partners in the development of technological fluency. The International Journal of Learning and Media, $1(2), 55-77$.

Barron, B. \& Martin, C. K. (2016). Making Matters. A Framework for the Assessment of Digital 
Media Citizenship. In K. Peppler, E.R. Halverson, \& Y. Kafai (Eds.) Makeology: Makers as Learners. Pp.45-71. New York: Routledge.

Barron, B. \& Levinson, A. M. (2017). Media as a Catalyst for Children's Engagement in Learning at Home and Across Settings. In Gee, E., Takeuchi, L. \& Wartella, E. (Eds.). Children and Families in the Digital Age: Learning Together in a Media Saturated Culture (pp. 17-36). New York, NY: Routledge.

Brahms, L., \& Werner, J. (2013). Designing makerspaces for family learning in museums and science centers. In M. Honey \& D. Kanter (Eds.), Design, make, play: Growing the next generation of stem innovators (p. 71 - 94). London: Routledge

Bronfenbrenner, U. (1979). The Ecology of Human Development. Cambridge: Harvard University Press.

Brown, A., López, G. \& López, M.H. (2016). Digital Divide Narrows for Latinos as More Spanish Speakers and Immigrants Go Online. Washington, D.C.: Pew Research Center.

Charmaz, K. (2006). Constructing Grounded Theory: A Practical Guide Through Qualitative Analysis. London: Sage.

Dugan, T.E., Stevens, R. \& Mehus, S. (2010). From show, to room, to world: a cross-context investigation of how children learn from media programming. International Conference on the Learning Sciences, (1), 992-999.

Espinosa, L., Laffey, J., \& Whittaker, T. (2006). Language Minority Children Analysis: Focus on Technology Use. Final report published by CREST/NCES.

Patricia Gándara \& Kfir Mordechay (2017). Demographic Change and the New (and Not So New) Challenges for Latino Education. The Educational Forum, 81(2), 148-159.

Goldenberg, C., Gallimore, R. \& Reese, L. (2005). Using Mixed Methods to Explore Latino Children's Literacy Development. In Weisner, T. (Ed.). Discovering Successful Pathways in Children's Development: Mixed Methods in the Study of Childhood and Family Life. Chicago: University of Chicago Press, (pp. 21-46).

Guernsey, L., Levine, M., Chiong, C., \& Severns, M. (2012). Pioneering literacy in the digital Wildwest: Empowering parents and educators. New York: Joan Ganz Cooney Center.

Gutiérrez, K.D. \& Rogoff, B. (2003). Cultural Ways of Learning: Individual Traits or Repertoires of Practice. Educational Researcher, 32(5), 19-25.

Hidi, S. \& Renninger, K.A. (2006). The Four-Phase Model of Interest Development. Educational Psychologist, 41(2), 111-127.

John-Steiner, V. (2000). Creative collaboration. New York: Oxford University Press.

Katz, V.S. (2017). What it means to be "under-connected" in lower-income families. Journal of Children and Media, 11(2), 241-244.

Kenner, C., Ruby, M., Gregory, E., Jessel, J., \& Arju, T. (2007). Intergenerational learning between children and grandparents in East London. Journal of Early Childhood Research, 5(3), 219243.

Lee, J. \& Barron, B. (2015). Aprendiendo en Casa: Media as a Resource for Learning among Hispanic-Latino Families. New York, NY: Joan Ganz Cooney Center at Sesame Workshop.

Levinson, A. M. (2014). Tapping In: Understanding how Hispanic-Latino immigrant families engage and learn with broadcast and digital media (Doctoral dissertation). Retrieved from Stanford Digital Repository (http://purl.stanford.edu/bb550sh8053).

Levinson, A. M. (2017). Latino Immigrant Families Bridging Home and School Learning with Technology. In Gee, E., Takeuchi, L. \& Wartella, E. (Eds.). Children and Families in the Digital Age: Learning Together in a Media Saturated Culture (pp. 174-191). New York, NY: Routledge.

López, M. H., Gonzalez-Barrera, A. and Patten, E. (2013). Closing the Digital Divide: Latinos and Technology Adoption. Pew Hispanic Center: Washington, DC.

Moll, L. C. Amanti, C., Neff, D., \& González, N. (1992). Funds of knowledge for teaching: Using a qualitative approach to connect homes and classrooms. Theory into Practice, 31(2), 132- 
141.

Penuel, W. R., Kim, D., Michalchik, V., Lewis, S., Means, B., Murphy, R., Korbak, C., Whaley, A., \& Allen, J. E. (2002). Using technology to enhance connections between home and school: $A$ research synthesis. Prepared for the Planning and Evaluation Services, U.S. Department of Education. Menlo Park: SRI International.

Rideout, V. J. (2014). Learning at home: Families' educational media use in America. A report of the Families and Media Project. New York: The Joan Ganz Cooney Center at Sesame Workshop.

Rideout, V. J. \& Katz, V.S. (2016). Opportunity for all? Technology and learning in lower-income families. A report of the Families and Media Project. New York: The Joan Ganz Cooney Center at Sesame Workshop.

Roque, R. (2016). Family Creative Learning. In Peppler, K., Kafai, Y., \& Halverson, E. (Eds.) Makeology in K-12, Higher, and Informal Education. New York, NY: Routeledge.

Stevens, R., \& Penuel, W. R. (2010). Studying and fostering learning through joint media engagement. Paper presented at the Principal Investigators Meeting of the National Science Foundation's Science of Learning Centers, Arlington, VA.

Takeuchi, L. \& Stevens, R. (2011). The New Coviewing: Designing for Learning Through Joint Media Engagement. New York: The Joan Ganz Cooney Center at Sesame Workshop.

UNICEF (2017). The state of the world's children 2017: Children in a Digital World. United Nations Children's Fund. Pp. 12-39.

U.S. Department of Education, Office of Educational Technology (2017). Reimagining the Role of Technology in Education: 2017 National Education Technology Plan Update. Washington, D.C.: U.S. Department of Education.

Valdés, G. (1996). Con Respeto: Bridging the distances between culturally diverse families and schools: an ethnographic portrait. New York: Teachers College Press.

Valdés, G., Capitelli, S., \& Alvarez, L. (2011). Latino Children Learning English: Steps in the Journey. New York: Teachers College Press.

Vaughan, C., Gack, J., Solorazano, H., \& Ray, R. (2003). The effect of environmental education on schoolchildren, their parents, and community members: A study of intergeneration and intercommunity learning. Journal of Environmental Education, 34(3), 12-21.

Vygotsky, L. (1986). Thought and language. Cambridge, MA: The MIT Press.

Wright, J., Huston, L., Murphy, K.C., St. Peters, M., Piñon, M., Scantlin, R. \& Kotler, J., (2001). The Relations of Early Television Viewing to School Readiness and Vocabulary of Children from Low-Income Families: The Early Window Project. Child Development, 72(5), 1347-1366. 